\title{
Para que história da ciência no ensino? Algumas direções a partir de uma perspectiva sociopolítica
}

\author{
Cristiano B. Moura*
}

\section{Resumo}

A partir da consolidação do campo de História, Filosofia e Sociologia na Educação em Ciências, é possível notar a solidificação dos argumentos que se utilizam comumente para defender a utilização de abordagens históricas na Educação em Ciências. Considerando as mudanças pelas quais passou o mundo desde os primórdios do campo e o momento crítico que vivemos hoje, este ensaio teórico direciona-se a investigar outras perspectivas e argumentos podem ser construídos hoje para as abordagens históricas na Educação Científica. Para isso, inicialmente retomo os argumentos mais comuns para defender o uso de abordagens históricas na Educação Científica, analisando-os à luz de alguns avanços do campo. Apresento o emergente turno sociopolítico na Educação Científica, apreciando possibilidades de expansão dos argumentos analisados inicialmente, em diálogo com autores do turno sociopolítico da Educação Científica. Por fim, são apresentados cinco argumentos abrangentes sobre por que abordar a história da ciência na Educação Científica.

Palavras-chave: História da Ciência, Educação em Ciências, Turno Sociopolítico.

\footnotetext{
- Doutor em Ciência, Tecnologia e Educação. Docente do Programa de Pós-Graduação em Ensino de Ciências e Matemática e do Ensino Médio Profissionalizante do Centro Federal de Educação Tecnológica de Celso Suckow da Fonseca- RJ (CEFET/RJ). E-mail: cristiano.moura@cefet-rj.br. ORCID: https://orcid.org/0000-00017136-634X
} 


\section{Introdução}

Em 2022 completam-se 30 anos desde a publicação do artigo "History, Philosophy, and Science Teaching: the present rapprochement" por Michael Matthews em 1992, na então recém-criada revista Science \& Education (MATTHEWS, 1992). Este artigo foi traduzido para português e publicado em 1995 (MATTHEWS, 1995) no Caderno Catarinense de Ensino de Física, e tornou-se referência quase obrigatória aos professores e professoras de ciências que buscam desenvolver pesquisas e intervenções didáticas em uma perspectiva histórica. Sem dúvidas, trata-se de uma brilhante síntese de todo o potencial das abordagens históricas para a educação em ciências e um argumento potente de porque não se deveria relegar a um plano acessório ou de menos importância a historicidade do conhecimento científico em seu ensino.

Hoje, seguindo os parâmetros de Fensham (2004), pode-se afirmar que existe uma subárea dentro do campo de pesquisa em Educação em Ciências que propõe a articulação da História, Filosofia e Sociologia da Ciência (HFSC) ${ }^{1}$ no Ensino e que este é um campo bastante consolidado (MOURA, 2019a). Com a consolidação do campo, veio a solidificação dos argumentos que se empregam comumente para defender a utilização de abordagens baseadas em HFSC. Dentre esses argumentos estão a perspectiva de humanizar o conhecimento científico, combater a história de uma ciência fundamentalmente progressiva, linear e de grandes feitos, expondo os embates e controvérsias que tiveram lugar na história de produção do conhecimento científico (MATTHEWS, 1995; GIL-PÉREZ et al., 2001).

Não há dúvidas de que muitos desses argumentos continuam apropriados e bastante convincentes, por si só. Entretanto, se consideramos que o conhecimento científico é contextual, isto é, historicamente situado e em profundo diálogo com seu tempo, é mister também enxergar os próprios argumentos produzidos em nossa comunidade de Educação em Ciências de tal maneira. O mundo de cerca de 30 anos atrás é dramaticamente diferente do mundo atual. Reconhecendo isso, que outras perspectivas e argumentos podem ser construídos hoje para as abordagens históricas na Educação Científica?

Buscando explorar essa questão, proponho este ensaio, que está dividido em quatro partes. Na primeira parte, apresento alguns dos argumentos que comumente foram defendidos na literatura como razões pelas quais se deveria abordar a ciência em perspectiva histórica no ensino. Em seguida, perpasso por alguns marcadores 
dos tempos atuais que considero importantes de serem pensados na exploração da pergunta que guia o ensaio e apresento brevemente alguns movimentos na pesquisa em Educação em Ciências (EC) que avançam no diálogo com o tempo de crises que vivemos. Na segunda parte, imbuído do diálogo com a contemporaneidade e com os movimentos dentro do campo da EC, exploro uma revisão de alguns dos objetivos apresentados inicialmente para as abordagens HFSC na EC e busco expandir esses objetivos. Na terceira parte, dialogo com alguns movimentos historiográficos que podem potencialmente auxiliar na tarefa de construir uma EC mais politizada e politizante (MOURA, 2019b) e, na parte final, sintetizo os argumentos.

\section{Para que História, Filosofia e Sociologia da Ciência na Educação em Ciências? Repassando alguns argumentos históricos na área}

A área de HFSC na Educação em Ciências desenvolveu-se de maneira particularmente proeminente no Brasil e na América Latina. $\mathrm{O}$ artigo traduzido para 0 português, de Matthews (1995), por exemplo, possui mais que o dobro de citações em relação ao artigo original (MATTHEWS, 1992). Longe de ser evidência única, a edição latino-americana do principal congresso de HFSC e EC, do grupo International History, Philosophy and Science Teaching Group (IHPST), é a versão regional com maior número de edições até o momento, superando as edições europeia e asiática. Somam-se a essas, outras evidências do particular desenvolvimento dessa área em nosso subcontinente. Muito desse desenvolvimento esteve ancorado em premissas básicas acerca das vantagens de se utilizar HFSC na EC, conforme alguns desses estudos amplamente citados na literatura.

Conforme Matthews (1995), os que advogavam pela HFSC na EC já naquela época, argumentavam em favor de uma abordagem "contextualista", que tivesse em conta os aspectos éticos, sociais, históricos, filosóficos e tecnológicos quando do ensino das ciências. Matthews (1995) continua o argumento, afirmando que esse seria um argumento em favor do ensino, simultaneamente, de e sobre ciências, isso é, que incluísse a chamada Natureza da Ciência ( $\mathrm{NdC}$ ) em vez de apenas ensinar sobre os conceitos científicos. A abordagem contextualista contribuiria para a EC porque, em suas palavras: 
(1) motiva e atrai os alunos; (2) humaniza a matéria; (3) promove uma compreensão melhor dos conceitos científicos por traçar seu desenvolvimento e aperfeiçoamento; (4) há um valor intrínseco em se compreender certos episódios fundamentais na história da ciência -a Revolução Científica, o darwinismo, etc.; (5) demonstra que a ciência é mutável e instável e que, por isso, o pensamento científico atual está sujeito a transformações que (6) se opõem a ideologia cientificista; e, finalmente, (7) a história permite uma compreensão mais profícua do método científico e apresenta os padrões de mudança na metodologia vigente. (MATTHEWS, 1995, p. 172-173)

Além dos trabalhos de Michael Matthews, podemos ainda notar outros trabalhos que se tornaram muito influentes na literatura nacional, acerca dos benefícios das abordagens baseadas em HFSC na EC. Um deles é o de Roberto Martins, que em texto de 2006 (MARTINS, 2006), também amplamente citado, traz alguns argumentos em favor das abordagens históricas. Busco destacar alguns deles. Segundo Martins (2006), o estudo adequado de episódios históricos permitiria:

(1) "compreender as interrelações entre ciência, tecnologia e sociedade, mostrando que a ciência não é uma coisa isolada de todas as outras mas sim faz parte de um desenvolvimento histórico, de uma cultura, de um mundo humano, sofrendo influências e influenciando por sua vez muitos aspectos da sociedade" (p. xxi-xxii); (2) "perceber o processo social (coletivo) e gradativo de construção do conhecimento, permitindo formar uma visão mais concreta e correta da real natureza da ciência, seus procedimentos e suas limitações" (p. xxii); (3) "compreender que a ciência não é o resultado da aplicação de um "método científico" que permita chegar à verdade" (p. xxiii); (4) "a formação de uma concepção adequada sobre a natureza das ciências, suas limitações, suas relações com outros domínios.” (p.xxiv); (5) “Além de [...] ajudar a transmitir uma visão mais adequada sobre a natureza da ciência, a história das ciências [poderia] auxiliar no próprio aprendizado dos conteúdos científicos” (p. xxv)

Além dessas, haveria ainda outras vantagens, exploradas tanto no trabalho de Matthews (1995) quanto no de Martins (2006). Sem dúvida, essas razões já seriam suficientes para justificar a importância de trazer a HFSC ao EC. Afinal, considerando o atual estado de coisas, com instituições científicas e públicas sendo colocadas sob suspeita e a constante disseminação de notícias falsas sobre temas de saúde pública, meio ambiente, entre outros, parece bastante razoável a necessidade de entender mais sobre como a ciência é produzida e validada. Entretanto, vários desses argumentos são passíveis de questionamento. Por exemplo, o que seria uma concepção adequada de NdC? As ciências são tão diversas entre si (IRZIK; NOLA, 2011) e mudam tanto ao longo do tempo (ALLCHIN, 2011) que cabe questionar se há, de fato, alguma estrutura que se possa aprender sobre a natureza dessas ciências. Ainda: há, de fato, qualquer valor intrínseco em se aprender sobre o darwinismo? 
Quem estabeleceu esse valor? Se tal conhecimento é valorado, por razões históricas e culturais, que outros conhecimentos não são valorados da mesma forma por força de epistemicídios (SANTOS, 2008) cometidos ao longo da história? Estas são ponderações que serão aprofundadas em seguida. No entanto, o que queria destacar nesse primeiro momento é que, como estudos têm apontado (DOS SANTOS, 2009; MOURA et al., 2021), apenas entender como a ciência funciona desde um ponto de vista conceitual e epistemológico não tem se mostrado suficiente para que se alcance uma situação de justiça social e bem-estar coletivo².

No caso da pandemia da COVID-19, por exemplo, pudemos assistir a situações de absoluta desigualdade na disponibilidade de vacinas ao redor do mundo, bem como o profundo fosso no que diz respeito ao impacto econômico em diferentes estratos sociais. Conforme argumentam Moura et al. (2021), o desenrolar das controvérsias públicas a respeito da COVID-19 parecem mostrar que ainda que tivéssemos uma situação de literacia científica plena no Brasil, com conhecimento profundo da população sobre os aspectos epistemológicos do conhecimento científico (e não apenas seus "fatos indisputáveis"), ainda assim, talvez os traços de injustiça social que caracterizaram tão terrivelmente esse capítulo de nossa história não seriam diferentes. O que parece um exercício excessivamente especulativo, encontra lastro na realidade na medida que muitas das decisões que aprofundaram a pandemia no Brasil seguiram de posições do governo central, sem que restasse aos cidadãos muitas possibilidades de escolha sobre esse tema (MOURA et al., 2021).

Isso aponta para a necessidade de que, de alguma forma, alinhemos nossa bússola da Educação em Ciências com tais valores de justiça social e bem-estar coletivo, indo além de valores cognitivos associados à tomada de decisões. Considerando isso e ainda considerando que a literatura de Educação em Ciências vem apontando consistentemente os benefícios de se trabalhar a HFSC na EC, como poderíamos juntar tais benefícios de abordagens históricas aos objetivos e valores os quais planteamos nesse artigo? Felizmente, trazer ao centro do debate a questão da justiça social/ambiental e o bem-estar coletivo não é um movimento novo na Educação em Ciências. Conforme veremos na próxima seção, a situação de emergência (climática, social) que vivemos tem precipitado novos movimentos na Educação em Ciências que buscam superar essa realidade. 


\section{Desafios da contemporaneidade e a Educação em Ciências: mudanças em curso}

Antes de voltar à Educação em Ciências, é importante explicar mais claramente a que me refiro com o termo "desafios da contemporaneidade". Enquanto escrevo este artigo, chegam notícias sobre as enchentes, principalmente na Alemanha e Bélgica, que levaram mais de 100 pessoas a óbito. Ocupam as manchetes as afirmações de cientistas de que a aceleração do aquecimento global, de causa antrópica, aumenta a probabilidade de vivermos eventos extremos como esses. Com isso, já se iniciaram articulações entre os países ricos para que se acelere o corte de emissões de gases poluentes e para que se diminua o impacto da ação humana sobre a Terra. Longe de ser um episódio isolado, cabe notar que há 10 anos atrás, a região serrana do estado do Rio de Janeiro, onde fica a cidade de Petrópolis, em que moro hoje, foi atingida por evento extremo, de chuvas intensas, que causou a morte de mais de 900 pessoas. No ano passado, evento semelhante acometeu a cidade de Belo Horizonte, em Minas Gerais.

Seja como for, tornou-se impossível falar sobre contemporaneidade sem mencionar o tempo atual de profunda preocupação com a situação ambiental do mundo, que é crítica para os humanos; tampouco sem mencionar a situação de desigualdades que está entrelaçada com a destruição ambiental. Ademais, para além das mudanças climáticas, também vivemos um cenário de aprofundamento das desigualdades sociais ${ }^{3}$. Conforme argumento em outro artigo (MOURA, 2019b), independente de qual seja nossa postura - relevar este cenário ou tentar ativamente superá-lo - a educação em ciências produzirá algo que, ao fim, irá existir justamente em tal cenário. Assim, assumo aqui um lado, que é o de entender que é necessário nos aproximar cada vez mais de tais objetivos políticos da educação em ciências, que visam construir uma sociedade mais justa e menos desigual.

Tal posicionamento aproxima-se do que a literatura da Educação em Ciências tem chamado de Visão III de Alfabetização Científica. Conforme Sjöström e Eilks (2018), apoiando-se em Roberts (2007), a Educação em Ciências, há mais de 50 anos, vem advogando pela necessidade de alfabetizar cientificamente a população. Contudo, dentro dessa defesa, embora haja convergências, também houve características que distinguiam as diferentes orientações curriculares sobre o que seria mais importante nesse processo de alfabetização científica. Roberts (2007) propôs 
a distinção entre visão I e visão II de alfabetização científica: a primeira congregaria propostas em que o foco está fundamentalmente no aprendizado de conceitos e processos científicos para aplicação posterior; já a visão II estaria relacionada ao entendimento sobre a utilidade do conhecimento científico na vida e na sociedade, ao focar inicialmente no aprendizado de ciências a partir de contextos significativos aos aprendentes. A tensão entre ambas as visões estaria relacionada à disputa em relação aos objetivos (ou orientações curriculares) da educação em ciências: se voltada majoritariamente a preparar futuros cientistas (o que se harmonizaria mais profundamente com a visão I) ou se voltada a um objetivo mais democratizante ("ciência para todos") (SJÖSTRÖM; EILKS, 2018). Partindo desse contexto, Sjöström e Eilks (2018) propõem, a partir do reconhecimento de diversos movimentos na EC que convergem (ao menos nesse ponto), a existência de uma visão III de alfabetização científica. Tal visão estaria orientada a uma alfabetização científica crítica, o que envolveria, sobretudo, a percepção de contradições existentes na sociedade e a ação para mudar tais contradições, através do engajamento efetivo em ações sociopolíticas.

Embora Sjöström e Eilks (2018) proponham a chamada visão III de alfabetização científica mais como um organizador de diversos movimentos que vêm ocorrendo no campo do que propriamente uma nova proposta para o conceito, entendo que vale a pena aqui destacar alguns desses movimentos para apontar com mais clareza tal tendência. Hodson (2010), por exemplo, baseando-se em alguns de seus próprios trabalhos anteriores, propõe vários níveis de sofisticação para os currículos de ciências, o que significaria avançar entre diferentes capacidades enquanto estudante de ciências. Passo a resumi-las a seguir:

Nível 1: Analisar o impacto social das mudanças científicas e tecnológicas e reconhecer que a ciência e a tecnologia são, em grande medida, determinadas culturalmente.

Nível 2: Reconhecer que as decisões sobre o desenvolvimento científico e tecnológico são tomadas em busca de interesses particulares e que os benefícios para alguns podem levar ao prejuízo de outros. Reconhecer que o desenvolvimento científico e tecnológico está intimamente ligado à distribuição de riqueza e poder.

Nível 3: Desenvolver suas próprias visões e estabelecer suas próprias posições de valor.

Nível 4: Ser capaz de preparar-se e de atuar em questões sociocientíficas e questões ambientais (HODSON, 2010, p. 199) 
Proposição parecida de alfabetização científica crítica também foi realizada por Wildson dos Santos (2009). Baseado na filosofia de Paulo Freire, dos Santos (2009) avança com a ideia de que a Educação em Ciências deveria ir além de um objetivo de humanização com vistas a preparar cidadãos para uma sociedade profundamente baseada nos construtos científico-tecnológicos, indo em direção a uma visão clara sobre a educação em ciências como possuindo função sociopolítica. Tanto para dos Santos (2009), quanto para Hodson (2010), um componente fundamental dos currículos de ciências deve ser a preparação para ação sócio-política, ou seja, está previsto um componente de engajamento em questões sociais e políticas que envolvam a ciência. Tal sugestão deu origem às chamadas pedagogias ativistas na Educação em Ciências (BENCZE; ALSOP, 2014; MARQUES; REIS, 2016) que vêm ganhando terreno na área nos últimos anos.

Buscando refinar o próprio entendimento sobre o que seria o engajamento cívico propalado por diferentes autores na área de Educação em Ciências como um objetivo importante, Rudolph e Horibe (2016) circunscrevem tal engajamento cívico às chamadas questões de interesse público. Ou seja, o engajamento cívico envolveria influenciar questões de interesse público por meio de estruturas políticas existentes. Com isso, os autores, além de oferecerem uma definição mais precisa do que seria o engajamento cívico envolvendo temas científicos, ainda defendem uma expansão dos objetivos de aprendizagem do campo, que passariam a ir além do meramente conceitual ou mesmo epistemológico, indo em direção a um objetivo social e político (RUDOLPH; HORIBE, 2016).

Deixando de lado a adequação ou não de aderir a um idioma de Educação em Ciências que coloque como aspecto central a perspectiva de alfabetização científica o que atrai quase que instintivamente uma linguagem do déficit, do "analfabetismo" (CORBETT, 2008) -, cabe notar como um movimento importante que as diversas instâncias da Educação em Ciências pareçam estar convergindo a respeito da necessidade de embraçar um iminente turno sociopolítico neste campo (TOLBERT; BAZZUL, 2017). Ainda, Tolbert e Bazzul (2017) entendem que o turno sócio-político é quase um desdobramento das perspectivas socioculturais para a EC, que vinham se popularizando nas décadas passadas. De fato, Lemke (2001) já propunha, ao caracterizar as perspectivas socioculturais na EC, o entendimento da ciência como cultura, como instituição social que muda de acordo com o tempo e espaço e que possui valores e crenças. Nesse sentido, questões como tipos de pessoas que eram/ 
são atraídas para as culturas científicas a partir dos tipos de perguntas que se faz, ou a sub-representação de certos grupos no empreendimento científico bem como as relações com forças econômicas e políticas passam a ser pensadas como parte de questões importantes a serem inspecionadas tanto nas narrativas sobre a ciência quanto nas pesquisas em EC (LEMKE, 2001).

Tudo isso aponta para mudanças profundas no cenário da Educação em Ciências, que, por sua vez, estão em sintonia com as mudanças que ocorrem no sistema Terra, aqui entendendo a nós humanos como parte desse sistema. Ao mesmo tempo que a Terra sofre mudanças em escala geológica que ameaçam a existência humana nesse sistema, também é possível notar o aprofundamento de questões sociais sensíveis, como a desigualdade social, a ascensão de governos autoritários ao redor do mundo, entre outras. Considerando essas mudanças e as próprias mutações da EC, que novas perspectivas poder-se-ia admitir para a educação em ciências em perspectiva histórica? É precisamente esta questão que buscarei explorar na próxima seção.

\section{A Educação em Ciências vista desde um ponto de vista sociopolítico e suas implicações para abordagens históricas}

Em primeiro lugar, correndo o risco de ser redundante, retorno a uma premissa importante desse ensaio: busco aqui dialogar e expandir as razões pelas quais se defende a utilização de abordagens históricas na EC a partir de uma perspectiva sociopolítica. Isso significa que, conforme Gurgel (2020), reconheço a possibilidade de orientações curriculares plurais; portanto, não me ocuparei especificamente de orientações como o ensino conceitual a partir de abordagens HFSC, por exemplo. Dito isso, retornarei agora aos objetivos enunciados na primeira seção sobre as vantagens de trabalhar as ciências a partir de uma abordagem HFSC, primeiro analisando tais proposições à luz de literatura recente na área de HFSC no Ensino, e, em seguida, tomando referenciais do chamado turno sócio-político, particularmente Hodson (2010), para potencialmente expandir tais vantagens.

Analisando, em primeiro lugar, algumas motivações específicas exploradas por Matthews (1995) e Martins (2006), entendo que algumas delas podem ser revisitadas à luz das novas pesquisas sobre $\mathrm{NdC}$ na Educação em Ciências, de modo a complexifica-las. Se é correto afirmar que a ciência faz parte de um "processo social (coletivo) e gradativo de construção do conhecimento", é importante entender que 
a "real natureza da ciência" é algo que ainda permanece razoavelmente opaco aos filósofos, sociólogos e outros estudiosos que se ocupam de entender a ciência. A tensão entre permanência e mudança na ciência é, de fato, algo que complica todo e qualquer esforço de fixar uma imagem para a ciência. Se podemos afirmar algo sobre a ciência do século XXI em relação à ciência do início do século XX, é que continuam-se utilizando comunicações no formato de artigos para divulgar novos resultados produzidos pelos cientistas, por exemplo. Por outro lado, a complexidade (social, técnico-operacional) de empreendimentos como o LHC (Large Hadron Collider) e outros artefatos da chamada Big Science complicam qualquer aproximação entre os dois períodos no que tange asseverar a "real" natureza de como se constrói a ciência, sob pena de simplificação inadequada. Também por isso, o projeto de "ajudar a transmitir uma visão mais adequada sobre a $[\mathrm{NdC}]$ " também entra sob suspeita. Sem dúvida, conhecemos razoavelmente bem muitas visões inadequadas sobre a ciência desde bastante tempo atrás (GIL-PÉREZ et al., 2001), mas dada a diversidade das ciências hoje (embora também no passado), será que faz sentido tentar transmitir uma "visão mais adequada"? Qual seria essa visão? A visão estrutural de Thomas Kuhn ou de Ludwik Fleck ou, ainda, versões menos estruturais como de Harry Collins ou Joseph Rouse? Se recuperamos o debate sobre por que motivo começamos a trabalhar temas de epistemologia da ciência em sala de aula, encontraremos argumentos relativos a melhorar a tomada de decisões sobre temas científicos, preocupações com um possível absolutismo científico (no sentido proposto por Oreskes, 2019), entre outras. Tais preocupações remetem à necessidade de garantir que a ciência trabalhe em favor de um bem-estar coletivo, o que diz respeito, precisamente, a discutir que posição a ciência deve ocupar na sociedade. Assim, mais do que incutir esta ou aquela visão sobre como funciona a ciência, o papel da educação científica deveria ser abrir uma discussão sobre os rumos da sociedade, em primeiro lugar, e o papel das ciências nessa sociedade. Ou seja, não se trata exclusivamente de um objetivo de conhecer algo, mas de reconhecer-se em um papel ativo na construção da sociedade, a partir da discussão de seus rumos, nesse caso, uma discussão fundamentada na História.

Ainda sobre as motivações listadas por Matthews (1995), encontramos diversas vantagens relacionadas ao conhecimento, ora conceitual ("compreensão melhor dos conceitos científicos"), ora epistemológico ("compreensão mais profícua do método científico"; “demonstra que a ciência é mutável e instável”). A estes objetivos, não 
quero contrastar outros, mas cabe observar que as perspectivas emergentes sobre educação em ciências apontam para um ensino que seja capaz de transitar entre os níveis de sofisticação de que Hodson (2010) trata; para isso, os objetivos de conhecimento não são suficientes; há que se trabalhar na discussão de valores, percepção de questões mais amplas relacionadas ao bem comum, entre outras. Se Hodson (2010) aponta, por exemplo que, em um primeiro nível, é importante analisar o impacto social das mudanças científicas e tecnológicas e devemos reconhecer o imbricamento cultural das ciências, entendo que esse é um chamado não apenas a contemplar a ciência desta ou daquela maneira, mas a analisar o impacto histórico do empreendimento científico em diversos momentos de seu desenvolvimento.

Por exemplo, é hoje conhecido que as expedições de colonização das Américas no século XVI e posteriores foi responsável por um fluxo sem precedentes de espécies animais e vegetais entre os continentes (LEWIS; MASLIN, 2016), levando a uma alteração de ecossistemas, uma nova distribuição de doenças, antes restritas a determinados lugares, entre diversas outras alterações significativas no sistema Terra. Do ponto de vista cultural, nota-se que ainda ligado a esse processo de colonização, está a expansão dos domínios do próprio conhecimento científico. Pimentel (2007) localiza na ampliação de horizontes decorrente das chamadas Grandes Navegações grande parte da que se produz no mesmo período na ciência. A premissas do universalismo, pilar essencial para a consolidação da Ciência Moderna Ocidental como conhecemos hoje, se estabelece a partir do apagamento de diferentes formas de conhecer o mundo, no processo de colonização; assim, o universal se constitui a partir da invisibilidade da diversidade epistemológica, ontológica e cultural que constituía o mundo naquele momento e ainda hoje (SANTOS, 2008). Sendo assim, mais do que contemplar a construção do edifício científico, podemos atender ao chamado de Hodson (2010) e buscar entender, através da História (da ciência), a extensão dos impactos sociais e culturais das mudanças científicas, que, por sua vez, eram também determinadas culturalmente. Assim, a partir desse episódio, podem-se discutir questões como: o que significou tal fluxo de espécies no mundo para o equilíbrio do sistema Terra, quais são suas consequências até hoje e como isso se reverteu (ou não) em benefícios para as diferentes populações (humanas e não-humanas) ao redor da Terra? Muito mais do que algo restrito a episódios específicos, questões de mesma natureza podem ser feitas para as mais diversas ocasiões na química, por exemplo, uma ciência que se desenvolveu em grande medida em 
par com o desenvolvimento industrial - uma tecnociência por excelência; ainda, a física, com suas conexões com a engenharia e o seu mergulho em corridas espaciais que possuem íntimas ligações com processos políticos e culturais que ocorrem de tempos em tempos. Explorar tais conexões não implica necessariamente gerar juízos de valor ou perder-se em avaliações maniqueístas ou meramente acusatórias em relação às ciências, mas sim pressupõe explorar as complexas relações entre ciência e sociedade de forma que os espaços de ensino e aprendizagem de ciência sejam também espaços de discussão sobre a sociedade, de maneira mais ampla - incluído aí o papel da ciência nessa sociedade. Com tais avaliações, é possível discutir-se quais tipos de ciência devemos priorizar em nossas sociedades e que futuros queremos buscar com tais escolhas.

No segundo nível proposto por Hodson (2010), entende-se como importante reconhecer os interesses particulares que por vezes se impõem sobre os benefícios a uma maioria, ou, de outra forma, busca-se escrutinizar as conexões entre as decisões sobre desenvolvimento científico e a distribuição de riqueza e poder. Aqui, a história da saúde e das doenças, sem dúvida, nos fornece um material interessante para essa discussão. Como tem sido ao longo da história a distribuição de financiamento entre a pesquisa sobre as chamadas doenças negligenciadas se comparado e o que se gasta com pesquisas a respeito de cosméticos? Longe de ser algo que se relaciona apenas a financiamento, a questão do poder está presente na própria ciência. Oreskes (2019) mostra como a pesquisa científica em relação a anticoncepcionais masculinos foi abandonada após indícios de alterações de humor durante o uso da medicação, conforme evidências; ocorre que o mesmo tipo de evidência foi descreditado e descartado na pesquisa sobre anticoncepcionais femininos, levando, portanto, ao avanço dos anticoncepcionais femininos e não os masculinos. Com isso, não pretendo apontar (tampouco Oreskes) que a ciência não é digna de confiança, mas sim que, conforme lições dos estudos feministas da ciência (HARDING, 2015), multiplicar os sujeitos que participam da construção da ciência pode contribuir para uma objetividade forte, isso é, a minoração dos fatores subjetivos que são intrínsecos à atividade de qualquer cientista. Isso significa empoderar outros sujeitos e grupos sociais, portanto, uma questão relacionada à distribuição de poder na sociedade. Aqui, há que se considerar a pluralidade de ciências que existem e seus diferentes objetivos e impactos na sociedade: a Engenharia Genética é ciência tal qual a Ecologia; ciências como a Geo-Engenharia possuem diferentes linhas de pesquisa. 
Essas diferentes ciências e linhas de pesquisa representam (ou representaram) quais impactos e quais objetivos na sociedade? O que podemos aprender a partir dessas considerações no sentido de avaliar a sociedade de forma mais ampla, suas estruturas de poder e de manutenção das desigualdades (sociais, econômicas, de gênero, classe e raça), e de que forma as diferentes ciências podem ajudar nesse processo de diminuição das desigualdades?

Quanto ao nível 3 e nível 4, Hodson (2010) chama atenção para a necessidade de desenvolver visões autônomas, posições de valor, e, a partir dessas, desenvolver a capacidade de atuar em questões sociocientíficas e ambientais. De fato, o autor preocupa-se com a possibilidade de doutrinação de estudantes, tendo em vista os temas sensíveis que em geral são tocados quando se abordam questões sociocientíficas, por exemplo. Baseando-se em Zeidler e colaboradores, Hodson (2010) aponta que, considerando que a doutrinação de estudantes é moralmente inaceitável e, de outro lado, uma educação sem valores é impossível, os estudantes deveriam ser ensinados a tratar questões controversas de maneira racional, diligente, tolerante, moral, analisando diferentes pontos de vista, reconhecendo inconsistências, contradições e inadequações para alcançar suas próprias conclusões. Isso sem falar sobre as questões relacionadas ao afeto (ALSOP, 2005) e que ultrapassam a ética meramente do discurso (OLIVEIRA; QUEIROZ, 2016), que também precisam estar na pauta. De toda forma, trabalhar com casos históricos, conforme Allchin (2011) argumenta, sem dúvida é uma fonte excelente de recursos para exercitar tais posicionamentos, atitudes e valores. Em relação ao nível 4, que compreende a ação sociopolítica - aqui pressupõe-se a organização para ação, e ação efetiva para que se evite a posição de "críticos de poltrona" -, penso que, salvo melhor avaliação, o estudo de episódios históricos talvez não tenha tanto a contribuir diretamente, mesmo em casos que mostrem algum tipo de situação que se repita no presente, como são os casos de machismo na ciência, etnocentrismo, entre outros. Embora o conhecimento da dimensão histórica dos problemas seja importante, este parece estar mais associado ao âmbito dos níveis menos sofisticados apontados por Hodson (2010). Assim, os episódios históricos podem ser bons aliados na construção de argumentos (historicamente) embasados, na percepção de injustiças históricas e contemporâneas e na construção de ligações afetivas com atores históricos humanos e não-humanos que seguem em posições vulneráveis na atualidade. Afinal, conforme Chang (2021) propõe, a história da ciência, "como os funerais, é para os vivos", ou 
seja, quando produzimos narrativas em $\mathrm{HC}$, visto que tais narrativas são sempre orientadas a algum objetivo específico, estamos inevitavelmente em diálogo com as questões da atualidade.

A partir de levantamento de tendências da Educação em Ciências aqui realizado, é possível apontar que, se adotamos uma perspectiva sociopolítica para a EC, novas perspectivas surgem para o campo da HC e Ensino. Cabe notar que tal argumentação nos levou a advogar principalmente por aspectos sobre a ciência que estão no domínio "não-epistêmico", conforme classificação de Erduran e Dagher (2014). Tal fato não é acidental: conforme notado por Gandolfi (2019a), tais aspectos ficam mais salientes do que os aspectos epistêmicos quando são levadas em conta preocupações com os ambientes interculturais de escolas e os aspectos políticos da construção do conhecimento.

No entanto, tais aspectos não derivam diretamente de toda e qualquer abordagem de História da Ciência. Retomando Gurgel (2020), assim como existem diferentes ênfases curriculares, também há plurais histórias das ciências que, assim, alinham-se e desalinham-se a cada uma das ênfases curriculares propostas por Gurgel (2020). São essas ênfases: formal, que privilegia o domínio dos aspectos formais de uma ciência, em que se espera um pensamento racionalmente estruturado; epistemológica-conceitual, que envolve a compreensão dos fundamentos conceituais das ciências; filosófica-cultural, que reúne discussões sobre as características das ciências e suas relações com outras manifestações culturais; habilidades científicas, que considera que saber [ciências] é dominar habilidades típicas da prática científica; cotidiano, que destaca a compreensão do cotidiano como um objetivo em si; CTSA-QSC, que defende que saber ciências é refletir sobre as relações entre Ciência, Tecnologia, Sociedade e Ambiente (CTSA), transformando este saber em práticas políticas através de uma cidadania ativa; e identitária, que considera que o currículo é um processo de formação de identidades, no qual a construção de relações subjetivas com o conhecimento é um elemento importante. Assim, uma história intelectual, que busca reconstruir os detalhes da construção de determinados conceitos, com atenção minorada aos aspectos culturais e sociais, deve estar mais bem alinhada a uma perspectiva formal ou epistemológica-conceitual do que a uma perspectiva identitária, por exemplo.

Partindo dessa observação, é útil tentar identificar, dentro da pluralidade de historiografias que caracteriza a História da Ciência na contemporaneidade, aque- 
las que favorecem as ênfases curriculares que mais aproximam-se à perspectiva sociopolítica à qual nos alinhamos neste ensaio. Cabe notar a esse respeito que nem as ênfases curriculares caracterizadas acima são totalmente estanques, tampouco uma perspectiva sociopolítica prescinde inteiramente de aspectos epistêmicos ou mais formais do conhecimento. Por isso são tratadas como ênfases (realces, relevos) e perspectivas (uma vista específica, dentre outras) que carregam consigo a possibilidade do plural e do híbrido. Na próxima seção trataremos brevemente de duas historiografias emergentes que cumprem o papel sociopolítico advogado nesse ensaio.

\section{Historiografias emergentes como aliadas no turno sociopolítico da Educação em Ciências}

Dentro do campo da História da Ciência, existem pelo menos dois movimentos historiográficos que vêm se destacando ao serem trazidos à Educação em Ciências com a intenção de buscar uma aproximação com as perspectivas sociopolíticas que exploramos nesse ensaio.

Começando pela História Global das Ciências, tal perspectiva historiográfica busca descrever o empreendimento científico como um produto de trocas materiais e cognitivas, apropriações, colaborações entre diferentes tradições culturais, e circulação entre diferentes tipos de conhecimento ao redor do mundo, promovidos em contextos geográficos e históricos (GANDOLFI, 2019b). Trata-se aqui de uma perspectiva que volta as lentes da História para processos globais que, conforme Gandolfi (2019b) ressalta, não tem a pretensão de afirmar uma universalidade do conhecimento produzido pela ciência, mas sim o reconhecimento das diferentes contribuições para a produção de tal conhecimento, inclusive atores humanos e não-humanos. A partir de Roberts (2008) é possível notar um programa decolonial/ pós-colonial nessa abordagem. Ela nasce com a preocupação de trazer ao centro das narrativas a questão do imperialismo, os processos de colonização, entre outros aspectos que buscam fazer justiça em relação aos apagamentos que possam ter ocorrido nas narrativas hegemônicas sobre ciência.

Ao transpor a História Global das Ciências à EC, Gandolfi (2019a) busca harmonizar esta proposta a perspectivas interculturais para a EC. Com isso, perguntas como: “como se sabia o que sabia?", “como esse conhecimento chegou na Europa?”, entre outras, buscam explorar os fluxos de conhecimento e recursos ao redor do 
mundo, bem como escrutinizar as contribuições de diversos povos para a construção do conhecimento científico

Já a História Cultural das Ciências é descrita por Moura (2019a) como uma perspectiva traçada a partir da vertente da História Cultural, representada por Peter Burke, por exemplo (dentre outros), em que a partir de um viés preponderantemente microhistórico, tem-se a atenção voltada a fazeres cotidianos de determinada prática cultural em análise. No caso das ciências ${ }^{5}$, a partir dessa abordagem historiográfica, o foco da análise a ser implementada são as ações produzidas pelos diferentes atores da ciência e mesmo aqueles atores sociais antes não incluídos nas análises sobre a ciência (trabalhadores manuais, técnicos, assistentes, tradutores e divulgadores, entre outros). Ao apostar muitas vezes em uma história narrada na "voz passiva" (MOURA, 2019a) são privilegiadas as descrições dos aspectos culturais e materiais das práticas científicas, isto é, das práticas em torno aos instrumentos e técnicas usadas nos laboratórios ou ao registro de dados, das comunicações estabelecidas entre os cientistas tanto para discutir quanto para divulgar seus trabalhos, da construção de ferramentas matemáticas de análise, de representação e construção de modelos, entre outras (MOURA; GUERRA, 2016). Assim, leva-se ao entendimento de como os cientistas disseminam suas ideias, como estabelecem relações sociais com outros cientistas e não-cientistas e como essas diversas práticas do cotidiano constroem o conhecimento científico, bem como destaca os diferentes atores incluídos nessas práticas.

Quando levada à EC, as premissas da História Cultural das Ciências, na leitura de Moura (2019a), imbuído de um olhar pós-colonial, levam ao desenvolvimento de narrativas históricas que deslocam de seu núcleo principal os grandes nomes da ciência e como estes atuaram para o estabelecimento de novas teorias, colocando em seu lugar as práticas e representações científicas, através da cultura material e visual, e como estas mudaram ao longo do tempo. Com isso, é possível traçar as rotas que nos permitam entender como a ciência se sustentou social, cultural e temporalmente, com atenção principalmente aos apagamentos e assimetrias de poder. Isso possibilita encaminhar questionamentos sobre a quem foi permitido e a quem foi negado participar de tal história, o reconhecimento (e possível reabilitação) de epistemes marginalizadas, entre outras.

Ambos os movimentos historiográficos representam o redirecionamento das ênfases a novas questões que se localizam mais preponderantemente, conforme argumentado, no campo do não-epistêmico e que se alinham, conforme Moura et al. 
(2021) argumentam, ao turno sociopolítico da EC. Cabe ressaltar que, se por si só tais movimentos representam oportunidades do campo HFSC na EC para aproximar-se de uma perspectiva sociopolítica, ao mesmo tempo a "(re)descoberta" da história como fonte potencial de discussões fundamentais para o presente e futuro, pode ser capaz de polinizar os demais campos da EC, convidando-os a explorar a dimensão histórica de seus problemas. Como falar de descolonização do conhecimento sem ir a fundo nos processos coloniais ${ }^{6}$ que lhes sustentaram ou sem buscar construir o que foi apagado a partir das narrativas hegemônicas? Como propor a interculturalidade e o convívio na diversidade sem explorar as assimetrias históricas de poder que subalternizaram determinadas manifestações culturais em comparação a outras? Com isso, não proponho aqui um reducionismo pobre de diferentes linhas de pesquisa às perspectivas da HFSC na EC, mas chamo a atenção para o desperdício de não se explorarem de forma profunda e sistemática tais intersecções. Há, no entanto, bons exemplos a esse respeito como os trabalhos em história da química de Silva e Pinheiro (2018) e Pinheiro (2020). Um olhar sistemático para a literatura certamente deve encontrar mais trabalhos além desses, visto que a linha de diversidade e multiculturalismo tem apresentado fôlego renovado nos últimos anos (NASCIMENTO; GOUVÊA, 2020).

As duas linhas historiográficas brevemente apresentadas aqui são, certamente, apenas duas possibilidades dentre outras de acercar-se a um turno sociopolítico na EC. Além disso, há muito trabalho a ser feito (muitos deles já estão em progresso) a respeito de como efetivar tais abordagens na educação básica, na formação de professores, nas políticas de currículo, entre outros espaços. O que pretendi aqui foi apenas apontar brevemente as iniciativas que já existem e que buscam alinhar-se à perspectiva sociopolítica apresentada nesse artigo. Passo, na próxima seção, a sintetizar os movimentos deste ensaio.

\section{Em direção a uma síntese}

Propus neste ensaio retomar os argumentos mais comuns para defender o uso de abordagens históricas na Educação Científica e explorar que outras perspectivas e argumentos podem ser construídos hoje para as abordagens históricas na Educação Científica, especificamente levando em consideração o emergente turno sociopolítico na EC. 
A partir da retomada de dois dos artigos mais citados no Brasil na área de HFSC na EC (MATTHEWS, 1995; MARTINS, 2006), em um primeiro momento avaliei seus argumentos a partir dos próprios avanços de tal área e, em um segundo momento, apreciei possibilidades de expansão de tais argumentos, em diálogo principalmente com Hodson (2010), que é um dos principais acadêmicos envolvidos no turno sócio-político da EC. A seguir, busco sintetizar esses argumentos sobre por que abordar a HFSC na EC, tanto os que endosso a partir dos artigos seminais, quanto os novos que busquei construir nas seções anteriores. Dessa forma, as abordagens históricas na EC podem:

- Ajudar a compreender as relações entre ciência, tecnologia, sociedade e ambiente como relações de co-produção, combatendo a visão de que o empreendimento científico seria uma "aventura desinteressada" no mundo do conhecimento. Tais relações são complexas e se expressam através dos sistemas de financiamento, da interação com instituições sociais diversas e estruturas de poder político, mas também através da (re)produção de estruturas, práticas e valores sociais que frequentemente estão ligadas a injustiças sociais e vão contra ao bem-estar coletivo.

- Ajudar na discussão sobre os processos de construção de conhecimento, buscando afastar o mito do "Método Científico" universal e homogêneo que permitiria chegar a verdades, e investigando seus procedimentos e limitações para compreender sua variabilidade ao longo da história de acordo com as condições materiais e culturais de cada tempo e espaço. Assim, poder-se-ia discutir que os modelos e práticas científicas são situados historicamente, sendo responsivos às questões de seu tempo, e que tais questões são, por sua vez, alimentadas por modelos anteriores e condições materiais específicas daquele tempo e espaço. Tal componente epistêmico (porém não exclusivamente epistêmico) é precisamente parte de uma compreensão melhor dos conceitos científicos, entendidos não como modelos e teorias acabadas, mas como objetos de conhecimento sustentados por longas redes de actantes.

- Avaliar a participação do empreendimento científico na conformação de como hoje a sociedade se relaciona com a natureza. Essa avaliação não pretende adotar simplesmente um tom acusatório à ciência - mesmo porque aqui adota-se um olhar para a ciência desde uma 
perspectiva de co-produção com as demais instituições sociais -, mas de buscar imaginar como esse papel pode ser repensado no presente e para 0 futuro (MOURA; GUERRA, no prelo). Isso implica também de reabilitar saberes e perspectivas de convivência com a Terra que foram dispensadas sem uma avaliação cuidadosa, mas somente por não atender aos cânones do saber europeu de determinadas épocas (SANTOS, 2008). Essa proposta vai além da perspectiva de humanizar a matéria, mas passa a reconhecer a natureza não como um objeto, como um recurso ao dispor dos humanos, mas como algo que participa da "dança da agência" (PICKERING, 2010) que perfaz os processos de construção da ciência.

- Ajudar a compreender os processos de invisibilização de determinadas contribuições à ciência a partir de narrativas que reconheçam tais contribuições. Assim, se buscaria simultaneamente promover a justiça social ao reconhecer tais contribuições, mas também expandir a narrativa sobre a construção da ciência, desafiando a ideia de cientistas como gênios isolados, mas indo além, ao reconhecer papéis que, de tanto serem forçados a um lugar subalterno, acabaram por ter sua contribuição relegada a um plano de menor importância para a produção do conhecimento. Aqui, localizam-se tanto os estudos que vêm ressaltando a contribuições de mulheres, pessoas negras (PEREIRA et al., 2019) e pessoas de orientações sexuais diversas ao padrão hetero-cis-normativo ${ }^{7}$, como também estudos que analisam contribuição de trabalhadores diversos (além de assistentes, instrumentadores e outros) em episódios de HC (FERREIRA, 2021).

- Auxiliar na busca por aproximações e distanciamentos entre as histórias que podem ser contadas sobre as ciências e as histórias de vida, condições sociais e aspectos das identidades dos estudantes. Em certo sentido, este benefício das abordagens HFSC segue do ponto anterior. Mais do que motivar e atrair os alunos, é importante que, entendendo os trajetos curriculares em sala de aula como processos de construção de subjetividades, busquemos aproximar as histórias contadas sobre as ciências das diferentes histórias dos próprios estudantes (MOURA, 2019a; MOURA et al., 2020). Com isso, pretende-se contribui para um potencial engajamento cívico (RUDOLPH; HORIBE, 2016) dos estudantes a partir de sua compreensão como sujeitos da História presente, ao perceberem-se refletidos em Histórias passadas. 
A partir dessa síntese, entendo que principalmente o primeiro e segundo ponto abarcam a maioria das contribuições anteriores, notadamente as contribuições seminais de Matthews (1995) e Martins (2006), enquanto os outros três pontos buscam avançar as potencialidades do campo HFSC e Ensino, ao dialogar diretamente com preocupações do presente, seguindo a trilha de uma historiografia ativista, conforme argumento de Chang (2021). Muitos desses pontos já vem sendo explorados em trabalhos tanto da História da Ciência quanto da Educação em Ciências. Busquei reconhecer alguns destes ao longo do texto. No entanto, certamente há muitos outros já publicados em desenvolvimento que não foram citados aqui, mas que fazem parte dos movimentos que busquei rascunhar brevemente nesse curto ensaio.

Não tratei nesse texto dos diversos contingenciamentos a que está sujeita esta proposta em temas como a formação de professores e a força das tradições disciplinares, o que, pela complexidade, certamente demandará esforços de pesquisa bem direcionados. Reconheço também que as próprias condições materiais e culturais, de maneira mais ampla, do fazer educativo no Brasil podem ser obstáculos a várias das propostas que argumento aqui, embora não tenha apontado caminhos específicos de implementação (que não são o objeto do ensaio). Isso porque não há dúvidas de que tais propostas demandam de nós, professores da educação básica, tempo para pesquisa, para planejamento cuidadoso, que inclui conhecer bem nossos alunos, oportunidade de avaliá-los de maneira apropriada, entre muitas condições que não estão disponíveis à maioria dos docentes em nosso país. Entretanto, espero que as ideias aqui descritas inspirem novas pesquisas nesses temas que criem outras evidências empíricas para corroborar ou contrapor tais vantagens que busquei traçar a partir de literatura anterior. Há, ainda, um longo caminho a percorrer na construção de uma Educação em Ciências orientada ao bem-estar coletivo (humano e não-humano) e à justiça social e ambiental e certamente a História, a Filosofia e a Sociologia das ciências podem ser poderosos aliados nesse caminho. 


\section{History of Science in Teaching - for what? Some directions from a sociopolitical perspective}

\section{Abstract}

Since the consolidation of the research field History, Philosophy and Sociology in Science Education, it is possible to notice the set of some arguments that are commonly employed to defend the usage of historical approaches to science education. Considering the changes the world has gone through in the last decades and the critical moment we live in today, this theoretical essay aims to investigate other perspectives and arguments that can be built today for historical approaches in Science Education. For this, I initially return to the most common arguments to defend the use of historical approaches in Science Education, analyzing them in the light of some arguments from this field. I present the emerging sociopolitical turn in Science Education, expanding the arguments initially analyzed, in dialogue with authors from the sociopolitical turn in Science Education. Finally, five comprehensive arguments are presented on why to approach the history of science in Science Education.

Keywords: History of Science, Science Education, sociopolitical turn.

\section{Notas}

1 Certamente há tensões entre os campos da História, Filosofia e Sociologia da Ciência em seus métodos de trabalho, modos de pensar e produzir conhecimento e objetivos. Tais tensões também existem quando tais campos do conhecimento são "traduzidos" em abordagens educacionais, o que resulta em diferentes apropriações da HFSC na Educação em Ciências. Apesar disso, opto por não entrar em tal debate nesse artigo. Aqui, sempre que me referir à história da ciência no ensino (ou abordagens históricas), me referirei indistintamente às abordagens de cunho exclusivamente histórico ou filosófico ou sociológico quanto às abordagens que buscam a integração desses campos.

2 Por evidente, aqui não imputo exclusivamente à perspectiva de ensino sobre as ciências (ou mesmo à Educação em ciências) a possibilidade de alcançar uma situação de justiça social e bem-estar coletivo, o que seria apostar em uma ilusória panaceia. No entanto, conforme argumento, tais objetivos deveriam estar no centro das preocupações da educação, seja ela científica ou não.

3 Para referências a estas e outras asserções com as quais traço o cenário geral, sugiro conferir Moura (2019a; 2019b).

4 Cabe notar aqui que opto por caminho similar ao de Hodson e Wong (2017) ao não fazer a distinção entre os processos pelos quais se faz a pesquisa científica e o conhecimento produzido por esses processos - definido na literatura como NOSK (Natureza do Conhecimento Científico, em tradução livre) e NOSI (Natureza da Investigação Científica, em tradução livre).

5 Entre os escritores que se alinham a essa vertente estão diversos autores como Juan Pimentel, Peter Galison, Ursula Klein, entre outros, que advogam tal abordagem em livros-chave de sua obra. Recentemente, foi anunciado ainda o lançamento de uma antologia de História Cultural da Química, coordenada por Peter J. T. Morris e Alan Rocke, o que é forte indício do impulso que tal vertente tem tido na literatura recente.

6 Ainda que a colonialidade, conforme Quijano (2009) vá além do momento histórico de colonização, é fundamental perceber os entrecruzamentos entre as diversas colonialidades que persistem e as colonizações históricas ocorridas, principalmente (em nosso contexto) nas Américas e na África.

7 Para conhecer mais sobre esse tema de pesquisa, recomendo o projeto "Transformational HPS" <www. transformationalhps.org >. 
ALLCHIN, D. Evaluating knowledge of the nature of (whole) science. Science Education, v. 95, n. 3, p. 518-542, 2011.

ALSOP, S. (Ed.) Beyond Cartesian Dualism: Encountering Affect in the Teaching and Learning of Science. Springer Science \& Business Media, 2005.

BENCZE, L.; ALSOP, S. (Eds.). Activist science and technology education. Springer Netherlands, 2014.

CHANG, H. Presentist history for pluralist science. Journal for General Philosophy of Science, v. 52, p. 97-114, 2021.

CORBETT, M. Captain Beefheart's piano: Confessions of an unrepentant illiterate. International journal of critical pedagogy, v. 1, n. 2, p. 148-159, 2008.

SILVA, L. H.; PINHEIRO, B. C. S. Produções científicas do antigo Egito: um diálogo sobre Química, cerveja, negritude e outras coisas mais. Revista Debates em Ensino de Química, v. 4, n. 1 , p. 5-28, 2018.

DOS SANTOS, W. L. P. Scientific literacy: a freirean perspective as a radical view of humanistic science education. Science Education, v. 93, n. 2, p. 361-382, 2009.

ERDURAN, S.; DAGHER, Z. R. Reconceptualizing Nature of Science for Science Education. Springer Netherlands, 2014.

FENSHAM, P. J. Defining an identity: The evolution of science education as a field of research. Boston: Kluwer Academic Publishers, 2004.

FERREIRA, P. P. A. L. O Eclipse de Sobral de 1919 a partir da História Cultural da Ciência: um desvio no caminho para uma Educação em Ciências problematizadora. 2019. Dissertação (Mestrado em Ciência, Tecnologia e Educação) - Diretoria de Pesquisa e Pós-Graduação, Centro Federal de Educação Tecnológica Celso Suckow da Fonseca, Rio de Janeiro, 2019.

GANDOLFI, H. E. Exploring and implementing an intercultural model of history of science to teach about nature of science. Unpublished PhD thesis submitted to UCL Institute of Education, University College London, UK, 2019b.

GANDOLFI, H. E. In defence of non-epistemic aspects of nature of science: insights from an intercultural approach to history of science. Cultural Studies of Science Education, v. 14, n. 3, p. 557-567, 2019a.

GIL-PÉREZ, D.; FERNANDEZ MONTORO, I.; CARRASCOSA ALÍS, J.; CACHAPUZ, A.; PRAIA, J. Para uma imagem não deformada do trabalho científico. Ciência \& Educação, v. 7, n. 2, p. 125-153, 2001.

GURGEL, I. Reflexões político-curriculares sobre a importância da História das Ciências no contexto da crise da modernidade. Caderno Brasileiro de Ensino de Física, v. 37, n. 2, p. 333-350, 2020.

HARDING, S. Objectivity and diversity. Chicago: University of Chicago Press, 2015.

HODSON, D. Science education as a call to action. Canadian Journal of Science, Mathematics and Technology Education, v. 10, n. 3, p. 197-206, 2010. 
HODSON, D.; WONG, S. L. Going Beyond the Consensus View: Broadening and Enriching the Scope of NOS-Oriented Curricula. Canadian Journal of Science, Mathematics and Technology Education, v. 17, n. 1, p. 3-17, 2017. DOI: 10.1080/14926156.2016.1271919

IRZIK, G.; NOLA, R. A family resemblance approach to the nature of science for science education. Science \& Education, v. 20, n. 7-8, p. 591-607, 2011.

LEMKE, J. L. Articulating communities: Sociocultural perspectives on science education. Journal of Research in Science Teaching, v. 38, n. 3, p. 296-316, 2001.

LEWIS, S. L.; MASLIN, M. A. Defining the anthropocene. Nature, v. 519, n. 7542, p. 171, 2015.

MARQUES, A. R.; REIS, P. Production and dissemination of digital videos on environmental pollution. Case Study: Collective research-based Activism. Revista Eureka sobre Ensenanza y Divulgacion de las Ciencias, v. 14, n. 1, p. 215-226, 2017.

MARTINS, R. A. Introdução: a história das ciências e seus usos na educação. In: Silva, C. C. (org.) Estudos de história e filosofia das ciências: subsídios para aplicação no ensino. São Paulo: Editora Livraria da Física, p. 17-30, 2006.

MATTHEWS, M. "História, filosofia e Ensino: a tendência atual de reaproximação". Caderno Catarinense de Ensino de Física, v. 12, n. 3, p. 164-214, 1995.

MATTHEWS, M. R. History, philosophy, and science teaching: The present rapprochement. Science \& Education, 1(1), p. 11-47, 1992.

MOURA, C. B. Educação Científica, História Cultural da Ciência e Currículo: articulações possíveis. 2019. Tese (Doutorado em Ciência, Tecnologia e Educação) - Diretoria de Pesquisa e Pós-Graduação, Centro Federal de Educação Tecnológica Celso Suckow da Fonseca, Rio de Janeiro, 2019.

MOURA, C. B. O Ensino de Ciências e a Justiça Social - questões para o debate. Caderno Brasileiro de Ensino de Física, v. 36, n. 1, p. 1-7, 2019.

MOURA, C. B.; GUERRA, A. Cultural History of Science: A Possible Path for Discussing Scientific Practices in Science Teaching? Revista Brasileira de Pesquisa em Educação em Ciências, v. 16, n. 3 , p. $749-771,2016$.

MOURA, C. B.; GUERRA, A. Rethinking Historical Approaches for Science Education in the Anthropocene. In: M. F. G. Wallace, J. Bazzul, M. Higgins, S. Tolbert (Eds.) Reimagining Science Education in the Anthropocene, NY: Palgrave MacMillan, no prelo.

MOURA, C. B.; NASCIMENTO, M. M.; LIMA, N. W. Epistemic and Political Confrontations Around the Public Policies to Fight COVID-19 Pandemic. Science \& Education, v. 30, n. 3, p. 501-525, 2021.

NASCIMENTO, H. A.; GOUVÊA, G. Diversidade, Multiculturalismo e Educação em Ciências: Olhares a partir do Enpec. Revista Brasileira de Pesquisa Em Educação Em Ciências, p. 469-496, 2020.

OLIVEIRA, R. D. V. L; QUEIROZ, G. R. P. C. Professores de Ciência como Agentes Socioculturais e Políticos: A Articulação de Valores Sociais e a Elaboração de Conteúdos Cordiais. Revista Debates em Ensino de Química, v. 2, n. 2, p. 14-31, 2016.

ORESKES, N., Why trust science? New Jersey: Princeton University Press, 2019. 
PEREIRA, L. S.; SANTANA, C. Q.; BRANDÃO, L. F. S. P. O apagamento da contribuição feminina e negra na ciência: reflexões sobre a trajetória de Alice Ball. Cadernos de Gênero e Tecnologia, v. 12 , n. 40 , p. $92-110,2019$.

PICKERING, A. The mangle of practice. Chicago: University of Chicago Press, 2010.

PIMENTEL, J. La Revolucíon Científica. In: ARTOLA, M. (Eds.) História de Europa: Tomo II. Madrid: Espasa Calpe, 2007. p. 163-238

PINHEIRO, B. C. S. O período das artes práticas: A química ancestral africana. Revista Debates em Ensino de Química, v. 6, n. 1, p. 4-15, 2020.

QUIJANO, A. Colonialidade do poder e classificação social. In: SANTOS, B. S.; MENESES, M. P. (Eds.) Epistemologias do Sul. Coimbra: Almedina, 2009. p. 73-118.

ROBERTS, D. A. Scientifc literacy/science literacy. In: ABELL, S. K.; LEDERMAN, N. G. (Eds.) Handbook of research on science education. Mahwah: Lawrence Erlbaum, 2007. p. 729-780

ROBERTS, L. Situating science in global history: Local exchanges and networks of circulation. Itinerario, v. 33, n. 1, p. 9-30, 2009.

RUDOLPH, J. L.; HORIBE, S. What do we mean by science education for civic engagement? Journal of Research in Science Teaching, v. 53, n. 6, p. 805-820, 2016.

SANTOS, B. S. A Ecologia de saberes. In: Santos, B. S. A Gramática do Tempo: para uma nova cultura política v.4. São Paulo: Cortez Editora, p. 137-165, 2008.

SJÖSTRÖM, J.; EILKS, I. Reconsidering different visions of scientific literacy and science education based on the concept of Bildung. In: DORI, Y. J.; MEVARECH, Z. R.; BAKER, D. R. (Eds.) Cognition, metacognition, and culture in STEM education. Chamonix: Springer, 2018. p. $65-88$.

TOLBERT, S.; BAZZUL, J. Toward the sociopolitical in science education. Cultural Studies of Science Education, v. 12, n. 2, p. 321-330, 2017. 